\title{
Educação em Ciência: actividades exteriores à sala de aula*1
}

\author{
Luís Marques \\ Departamento de Didáctica e Tecnologia Educativa. \\ luís@ua.pt \\ João Praia \\ Centro de Investigação Didáctica e Tecnologia na \\ Formação de Formadores. \\ jpraia@ua.pt
}

\begin{abstract}
SCIENCE EDUCATION: OUTDOOR LEARNING ACTIVITIES. The important role played in science education by outdoor learning environments is recognised by educational research; this environment is also frequently used by science teachers, particularly Earth Science teachers in their teaching strategies. Taking into account the lack of an accurate designation, in the Portuguese language, for the concept of outdoor learning environment, a suggestion is put forward, as follows: "Actividades Exteriores à Sala de Aula (AESA)". The study is developed in four steps: (1) challenges to science education in a social context and their implications for the teaching and learning process; (2) discussion about the nature of the outdoor learning environment, mainly in the field of Earth Sciences teaching and learning; (3) reflections on the contribution of outdoor learning environment activities for the achievement of the main aims concerned for science education; (4) final comments, mainly based on the science teaching and learning process, articulated with the need of a better interaction between educational researchers and science teachers. This cooperation facilitates the definition of guidelines which will optimize the relationship between outdoor learning activities and other teaching and learning activities and, therefore, improve Earth Sciences Education.
\end{abstract}

KEYWORDS Science education, outdoor learning environments, nature of the scientific knowledge, integration of knowledge, uncertainty and unpressibility, relevance of the natural environment, cooperative work.

*Este artigo deve ser referido como segue:

Marques L., Praia J. 2009. Educação em Ciência: actividades exteriores à sala de aula. Terræ Didatica, $5(1): 10-26<$ http:// www.ige.unicamp.br/ terraedidatica/>

1 A comunicação original (Marques e Praia 2007) constituiu palestra apresentada no I Simpósio de Pesquisa em Ensino e História de Ciências da Terra e Ill Simpósio Nacional sobre Ensino de Geologia no Brasil, em Campinas, setembro de 2007, tendo sido indicada pelos organizadores para ser publicada nesta edição de Terrae Didatica.
RESUMO O ambiente outdoor vem sendo reconhecido pela investigação como importante no âmbito da Educação em Ciência (EC) e é frequentemente usado pelos professores de ciências. Atendendo à ausência de uma designação em português que corresponda à natureza daquele conceito em língua inglesa, propõe-se aqui a de Actividades Exteriores à Sala de Aula (AESA). O estudo desenvolve-se em quatro momentos. No primeiro, apresentam-se alguns dos desafios colocados à EC e faz-se o seu enquadramento social, bem como se abordam as implicações em termos de ensino e de aprendizagem. No segundo, foca-se na discussão sobre a natureza dos ambientes exteriores à sala de aula, dando uma particular ênfase ao que ocorre no domínio das Ciências da Terra. De seguida, e num terceiro momento, reflecte-se sobre a contribuição das AESA na consecução das grandes finalidades sugeridas para a EC. A terminar, e num quarto momento, efectuar-se-ão comentários finais do estudo com particular ênfase no processo complexo do ensino e de aprendizagem, bem como na necessidade de uma melhor interacção entre investigadores educacionais e professores, em ordem a aproveitar, de forma articulada com outras actividades, as potencialidades das que são desenvolvidas fora da sala de aula. Em síntese, pretende-se contribuir para melhorar os resultados da Educação em Ciência no âmbito das Ciências da Terra.

PALAVRAS-CHAVE Educação em Ciência, actividades exteriores à sala de aula (AESA), natureza do conhecimento científico, integração de saberes, incerteza e imprevisibilidade, valorização do ambiente natural, trabalho cooperativo. 


\section{Introdução}

A presente comunicação desenvolver-se-á em quatro momentos. No primeiro, proceder-se-á a um breve enquadramento da temática em análise no contexto da Educação em Ciência. O segundo, centra-se na discussão da natureza dos ambientes externos à sala de aula, de uma forma muito especial, nas aqui designadas Actividades Exteriores à Sala de Aula (AESA), no âmbito das Ciências da Terra. O terceiro momento abordará a contribuição deste tipo de actividades para a consecução das finalidades apontadas para a Educação em Ciência. A terminar, far-se-á uma reflexão final sobre implicações do estudo realizado.

Será dada ênfase a uma abordagem de natureza mais conceptual e menos de índole empírica tendo em consideração, por um lado o déficit daquela reflexão na literatura sobre as $A E S A$ e, por outro, a sua relevância para o enquadramento de propostas de trabalho em consonância com indicadores da investigação educacional.

\section{Educação em Ciência: desafios na sociedade actual}

A referência à centralidade da educação na sociedade actual, entendida como promotora da construção da pessoa humana, não oferece, hoje, contestação, atendendo aos múltiplos desafios do futuro. A materialização desta ideia está, por exemplo, bem expressa, pelo facto de todas as conferências recentes das Nações Unidas - Rio de Janeiro, Beijing, Viena, Copenhague, Cairo - acordarem em proclamar, qualquer que fosse o tema em debate - meio ambiente, população, desenvolvimento social, direitos do homem e democracia, mulher ou alojamento - que a educação é a chave que permitirá inflectir o curso do mundo actual (Adanets 2001).

Contudo, não existe a mesma convergência de pontos de vista, no que respeita à natureza e às prioridades a dar às políticas educativas a seguir. Nesta lição, não se verá a educação como o remédio para um mundo, que se confronta com problemas graves, porque complexos, mas como "um entre outros caminhos e para além deles, como uma via que conduza a um desenvolvimento humano mais harmonioso, mais autêntico, de modo a fazer recuar a pobreza, a exclusão social, as incompreensões, as opressões, as guerras ..." (Delors 1996).

A reflexão a efectuar no âmbito desta secção será orientada, de acordo com o diagrama representado na figura 1. Começar-se-á por fazer um breve enquadramento da Educação em Ciência, sublinhar-se-ão implicações educacionais, em termos de ensino e de aprendizagem. Terminar-se-á com algumas notas sobre a importância de articular indicadores que emergem de diversas linhas de investigação em Didáctica das Ciências.

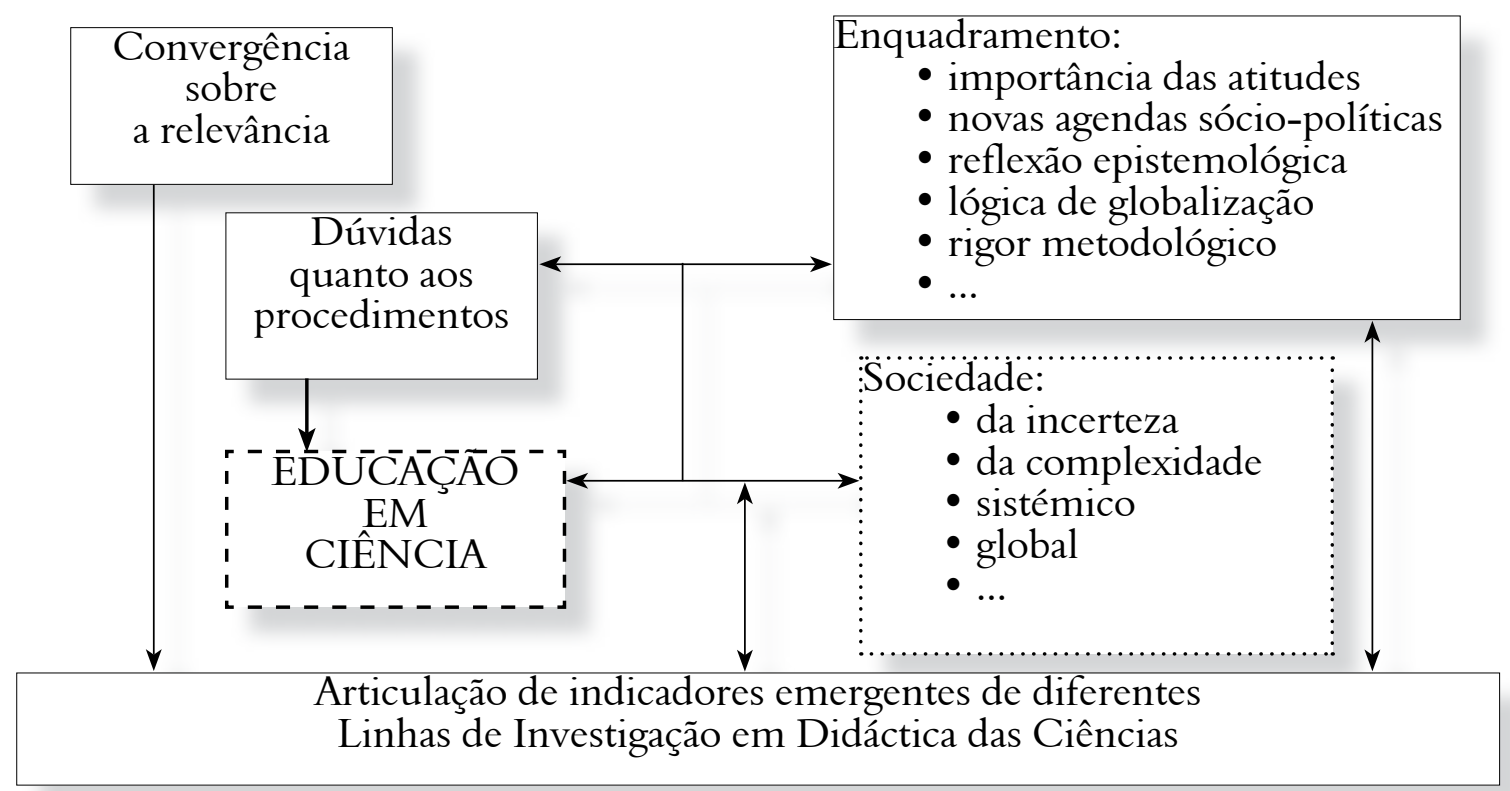

Figura 1 - Contextos, dificuldades e desafios que se colocam à Educação em Ciência 


\subsection{Enquadramento social da Educação em Ciência}

Incerteza, globalização, complexidade, perspectiva sistémica, ambiente, democracia planetária (Knorr-Cetina 1999, Morin 1999, 2001, Belitsos 2005, Marques et al. 2008) são, entre outros, referentes sociais que sustentam a Educação em Ciência e que balizam o desafio, com que se confronta a formação que os alunos deverão ir ganhando no decurso da educação formal.

Entende-se, aqui, educação formal como um programa de educação correspondente a um processo de formação e desenvolvimento pessoal, em termos de conhecimentos, capacidades e de carácter, no contexto de um programa estruturado $\mathrm{e}$ certificado (Glossary of Literacy Terms 1999). E o que se pretende discutir nesta comunicação passase no âmbito da educação formal.

E deve começar por se reconhecer que "o que é próprio do saber não é ver nem demonstrar, mas interpretar", sendo necessário "restituir a grande planície das palavras e das coisas", "fazer falar tudo", "fazer nascer, por sobre as marcas, o discurso ulterior do comentário" (Foucault 1996, p.95).

E como é, afinal, interpretada o contexto em que esse saber se encontra envolvido?

Sem pretender encontrar uma resposta simples e pronta a esta pergunta, propõe-se um conjunto de aspectos que deverão servir de matriz à necessária procura. Aspectos político-institucionais, epistemológicos, metodológicos, de cariz globalizante, dentre outros, não se compaginam senão com soluções diferenciadas, procuradas através de caminhos plurais, sempre num contexto de diversidade e de uma natural complexidade. É neste enquadramento que deverá ser entendida a posição de Morin (1999), quando afirma que o maior contributo de conhecimento do século XX foi:

- o reconhecimento dos seus próprios limites;

- a indispensabilidade de fazer convergir vários ensinos e mobilizar diversas ciências, para aprender a enfrentar a incerteza;

- o comprimir o calculável e o mensurável numa província do incalculável;

- o entendimento de que o homem é um ser limitado, executando um trabalho incerto num contexto igualmente incerto.

\subsection{Implicações educacionais em termos de ensino e de aprendizagem}

Sublinhando que as questões referentes à sociedade actual não foram referenciadas senão como exemplos, é verdade que daquelas emergem exigências claras para a Educação em Ciência e para a problemática desta comunicação, das quais se destacam:

- exigências relacionadas com o desenvolvimento económico e social, que é exigível na sociedade actual. De facto, a promoção do conhecimento, enquanto motor do bem-estar económico, passa seguramente pela promoção do conhecimento, enquanto valor social. Num plano colectivo, criar conhecimento e com este criar riqueza não será possível sem que, no plano individual, toda e qualquer sujeito procure conhecer e seja capaz de utilizar o que conhece em proveito próprio e do colectivo em que se insere (Canavarro 2004);

- exigências de ordem ética, sem as quais as relações de cada um, por um lado, com a natureza e, por outro, com e entre os diversos grupos sociais, poderão ser bem conflituosas, afastando-se perigosamente das desejáveis tendências de equilíbrio e de desenvolvimento harmónicos. Valores éticos são aqui tidos como uma centralidade e como reguladores da conduta e das representações do ser humano sobre o mundo, desejando-se que sejam elementos estruturantes da sociedade (Boavida e Sanches 1997);

- exigências de reconhecimento da necessidade de uma solidariedade internacional activa, para a qual também é indispensável a aquisição de uma visão global integrada num quadro de valores (Burbles and Torres 2004).

Caminhos para a consecução destas exigências terão de ser primeiro cuidadosamente pensados e depois operacionalizadas, com flexibilidade. Implicações são esperadas relativamente:

- à aquisição de valores e atitudes;

- à solução de problemas, à colocação de interrogações e ao questionamento;

- à tomada de decisões;

- às metodologias de trabalho a utilizar.

As possíveis respostas terão de ser procuradas 
num contexto, que tem uma componente de exigência económico-social, que precisa de ser analisada, segundo uma perspectiva ética e numa dimensão de efectiva solidariedade activa. Da literatura (Fraser e Tobin 1998, Hodson 2004, Cachapuz et al. 2002), aponta-se a inadequabilidade das propostas que valorizam a transmissão unidireccional de conhecimentos, admissíveis, porventura, num mundo que já não existe. Este, em que nos encontramos, coloca desafios novos, que deverão ter resposta a três níveis, que aqui não iremos desenvolver: o do currículo em geral, e do currículo de ciências em particular; o da formação de professores, em geral, e da formação de professores de ciências, em particular; o da investigação educacional, predominantemente a que visa a melhoria substantiva das práticas lectivas, numa tentativa de encontrar o enquadramento mais adequado destas.

Uma nota, oportuna nesta comunicação, relativamente à necessária importância de num currículo de ciências e, particularmente no de Ciências da Terra, se integrarem oportunidades de incluir propostas de trabalho a efectuar em ambientes fora da sala de aula.

The concept of using the outdoors as a vehicle for education is well established; the natural environment, and the adventurous situations we can place young people in, has been seen for many decades as providing as inspiring and challenging setting for education to take place (Gair 1997, p. 1).

As aqui designadas $A E S A$ correspondem ao ambiente outdoor da terminologia anglo saxónica:

outdoor to encompass any practical work occurring outside of the school laboratory, be this in the school yard, on the sports field or in the wider environment. This wider environment could include woodland or sand dunes, a quarry or shopping precinct, a zoo or a research laboratory (Lock 1998, p. 633).

Indispensável é pensar na formação de professores capazes de:

organizar contextos de aprendizagem exigentes e estimulantes, isto é ambientes formativos que favoreçam o cultivo de atitudes saudáveis e o desabrochar das capacidades de cada um com vista ao desenvolvimento das competências que thes permitam viver em sociedade, ou seja, nela conviver e intervir em interacção com os outros cidadãos (Alarcão 2001, p. 11).
O apoio da investigação educacional não deixa de ser relevante. Por um lado, ajuda a reconhecer que, quando os alunos são confrontados com situações de ensino e de aprendizagem, em espaços fora da sala de aula, onde se podem procurar explicações para os factos de uma forma diferente da que é habitual na sala de aula, porque mais integrados, explícitos e próximos da realidade natural, o seu entusiasmo e nível de envolvimento aumentam e isso traz reflexos favoráveis para a aprendizagem (Braund e Reiss 2004). Por outro lado, porque sem esquecer que a investigação não deve esgotar-se na procura de respostas para as questões imediatas que se colocam às práticas lectivas, é, contudo, de esperar que com elas revele fortes preocupações. Esse é um esforço notável em nível internacional e que tem igualmente ocupado um espaço assinalável no Departamento de Didáctica e Tecnologia Educativa da Universidade de Aveiro (Costa e Marques 1999, Costa et al. 2000, Costa 2003, Costa et al. 2003, Loureiro et al. 2005, Marques et al. 2005), esforço esse que veio a evoluir para a criação, em 2004, do Laboratório da Avaliação da Qualidade do Ensino.

\section{Investigação em Educação em Ciência e natureza das actividades exteriores à sala de aula}

A investigação no âmbito da Didáctica das Ciências tem vindo a ter um incremento notável (Lopes et al. 2005, Fensham 2004, White 2001, Jenkins 2000). É possível segundo alguns autores (Cachapuz et al. 2004), categorizar os trabalhos efectuados em grandes temas como, por exemplo: concepções alternativas, linguagem, perspectivas relativamente ao conhecimento científico, filosofia da ciência e sua natureza, desenvolvimento cognitivo, resolução de problemas, Ciência-Tecnologia-Sociedade, avaliação, trabalho prático (incluindo o experimental, o laboratórial, o de campo etc.).

A razão de ser da escolha da temática desta comunicação reside, por um lado, na relevância das potencialidades das $A E S A$ para a consecução das finalidades da Educação em Ciência, particularmente no que respeita a uma melhor compreensão e utilização do conhecimento científico e a uma efectiva valorização do ambiente natural (Marques 2006) e, por outro, na reconhecida insuficiência da investigação efectuada neste domínio (Orion 2002). 
A designação AESA indica que há uma contribuição conjunta dos vários ambientes de aprendizagem para a consecução das finalidades da Educação em Ciência. As questões aqui abordadas, sem ter a pretensão de definir de forma completa a globalidade dos referidos ambientes enquadram bem, do ponto de vista do autor, particularmente os que são mais frequentemente usados no âmbito da Geologia e Biologia - trabalho de campo, museus ao ar livre, museus de história natural, entre outros.

O diagrama da figura 2 expressa o desenvolvimento desta secção. Começar-se-á por referir a natureza do ambiente externo à sala de aula, passando à apreciação do respectivo impacte ao nível educacional. disciplinares em que, por exemplo, um certo tipo de trabalho laboratorial foi sendo sobrevalorizado. $\mathrm{E}$ isto porque, segundo autores, como Frodeman (2003), frequentemente se tem excluído de alguns domínios científicos aspectos subjectivos, como a interpretação, particularmente enquanto predominava o paradigma da física newtoniana.

Vejamos um exemplo do âmbito da Geologia, que, de certa forma, reflecte a posição anterior. As interpretações relativas às concentrações metalogénicas (jazidas metalíferas) opõem, de uma forma quase sistemática, naturalistas e fisico-químicos (Bernard 1977). Recorde-se que o princípio fundamental da modelização genética é explicar a formação das referidas concentrações, através do funcionamento,

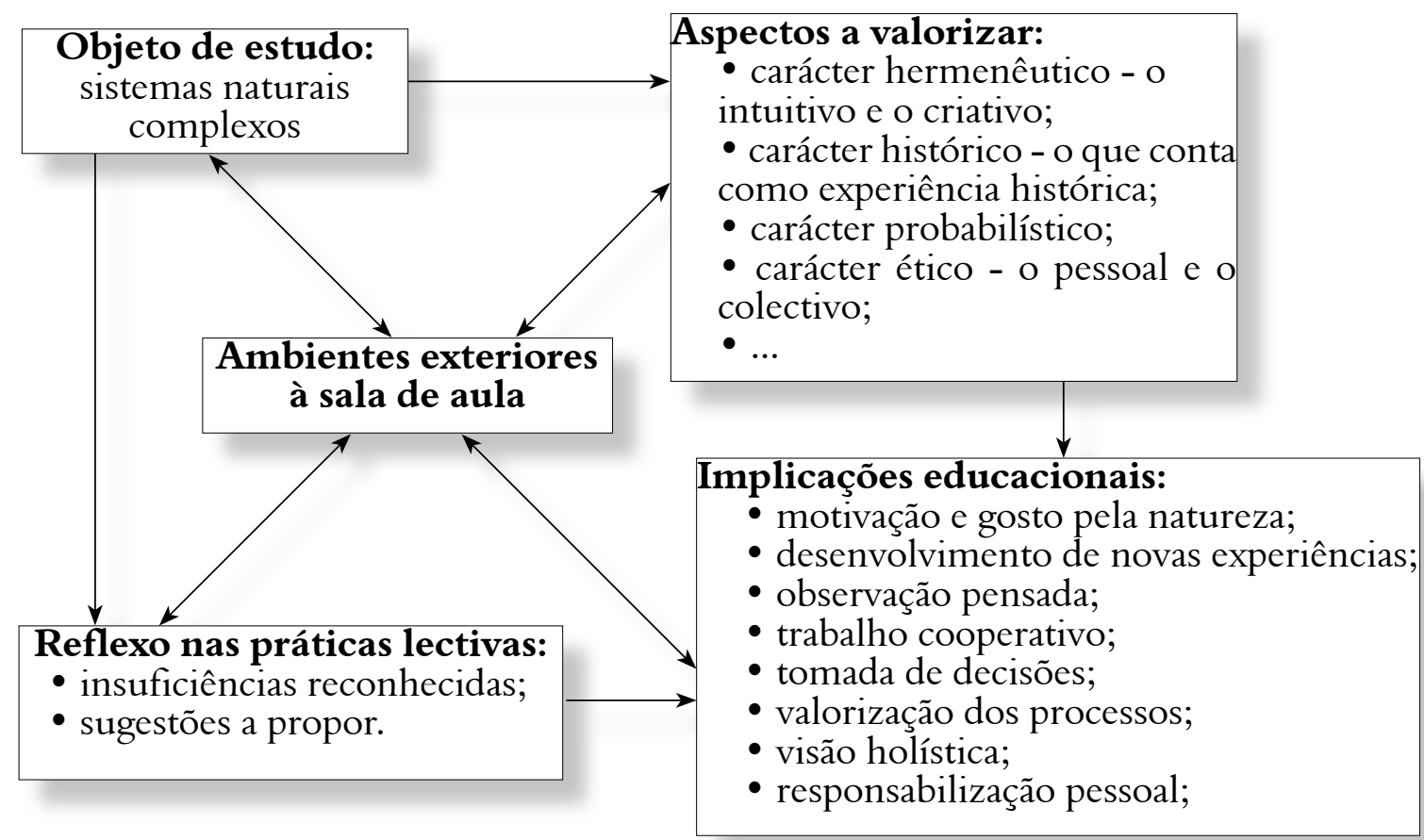

Figura 2 - Ambiente externo à sala de aula - do objecto de estudo a aspectos a potenciar e ao impacto ao nível das práticas lectivas

\subsection{Natureza dos ambientes exteriores à sala de aula}

Referir-se-ão agora características dos ambientes exteriores à sala de aula, bem como se procederá a um rápido enquadramento de uma das áreas disciplinares, na qual elas são mais pertinentes e na qual os autores têm vindo a trabalhar de um modo mais sistemático - as Ciências da Terra.

Sublinhe-se o facto das experiências de campo não se articularem com uma filosofia de ciência que foi sendo desenvolvida a partir de algumas áreas durante um certo tempo, de um conjunto de fenómenos físicos e químicos. E todo o modelo deverá explicar, quer a concentração química, quer as suas particularidades factuais. Eé ao nível da concepção genética que as perspectivas se dividem.

Os físico-químicos vêem os factos tal como eles podem hoje ser percebidos. O funcionamento dum sistema terá de explicar o que é observado e é por isso que o modelo explicativo é:

- monogénico - um conjunto único de fenómenos vai conduzir um estado de dispersão a um 
estado de concentração;

- fixista - admite como implícito que a concentração de facto observada é a que resultou do funcionamento do modelo.

Os geólogos naturalistas têm dúvidas quanto a esse entendimento. A atitude que revelam é distinta. A experiência da Paleontologia, a diversidade das condições de fossilização e conservação dos restos orgânicos, mas não só, fazem com que interroguem a fidelidade do registo - tanto se terá passado desde a própria formação!

A esta perspectiva está inerente a ideia de que, afinal, a história geológica das mineralizações não pode, por um lado, ser desligada do próprio enquadramento estéril daquelas e, por outro, deixar de assentar na interpretação de uma cronologia relativa da influência de grandes acontecimentos de diferenciação, de natureza sedimentar, metamórfica, magmática e, mesmo, pedológica. Está-se, assim, perante um modelo poligénico e transformista.

Com efeito, há todo um tratamento sistemático, do qual a subjectividade não está ausente. Subjectividade essa que, até ao recente desenvolvimento das ciências cognitivas, era um tema apenas visto como pertencente ao âmbito da filosofia e da psicologia.

A incerteza das respostas torna mais difícil a compreensão da génese das situações, o desenrolar da sua evolução. Essa incerteza ajuda a entender a necessidade de recorrer a uma interpretação com um grau de risco assumido.

Do ponto de vista epistemológico, tais situações terão um grau de falsificabilidade baixo. Os próprios sistemas naturais, independentemente das diferentes acepções que a fórmula "Sistema Terra" vem conhecendo (Pablos 2004), são inerentemente complexos, tal como complexa - não linear nem sistemática - é a sua resposta, às respectivas perturbações a que são sujeitos.

Ora, o que acontece quando se trabalha no campo é que, frequentemente, são situações deste tipo que estão registadas nos afloramentos. Estas necessitam de ser tratadas, de tal modo que não poderão prescindir duma observação rigorosa, mas igualmente de interpretações audaciosas.

As dificuldades de articulação entre todas as entidades em jogo chegam mesmo a reflectir-se no facto de muitos investigadores aceitarem que a imprecisão, inerente, por exemplo, ao raciocínio efectuado com base nos dados de campo, dever ser considerada uma deficiência, particularmente quando se estabelece a comparação com os métodos e os resultados de outras áreas do saber, tidas como exactas (Frodeman 2003). É que a peculiaridade daquele tipo de raciocínio reflecte-se em várias situações, algumas delas acabando por poder parecer altamente depreciativas, como, por exemplo, a ausência de contribuições para o aparecimento de leis quantitativas da natureza.

O que se procura aqui sublinhar é que precisamente as qualidades desse raciocínio, expressas nalgumas actividades externas à sala de aula, podem dar um contributo a um melhor entendimento da natureza e limitações do raciocínio humano, mas também oferecer a possibilidade de um discernimento profundamente hermenêutico, histórico, probabilístico e ético, tão importante na compreensão de nós próprios (Frodeman 1995). Referir-seão, em detalhe, cada um destes quatro aspectos.

\subsubsection{Carácter hermenêutico}

A palavra grega original significa anunciar, interpretar, traduzir (Bruger 1983). O carácter hermenêutico, fazendo interagir o intuitivo e o criativo, implica que a percepção que temos não pode ser pensada como um dado adquirido objectivamente, mas sim integrando já algum grau de interpretação, mais ou menos consciente, que emana de experiênciações anteriores e do que fica registado em memória. Toda a realidade natural, particularmente expressa no campo, corresponde a informação registada, que necessita de ser interpretada e depois descrita. Atente-se, por exemplo, na figura 3, que representa um magnífico afloramento sedimentar.

Trata-se de um afloramento com muita informação inscrita, necessitando de análise detalhada. Se se atentar no que, pelo menos em uma primeira observação, pode corresponder a eventuais lacunas estratigráficas, é preciso discutir o seu significado. Tratando-se de uma sedimentação efectuada em ambiente eólico ou aquático, o sentido dessas lacunas será diferente.

A forma como o referido afloramento é compreendido é sempre função da maneira como sobre ela nos projectamos, com o conjunto de instrumentos disponíveis, mas também com os conceitos, expectativas e valores que conosco transportamos.

Se, por exemplo, para o cálculo do tempo de deposição, se aceitar uma solução completamente enquadrada pelo princípio das causas actuais, então, e dentre outros elementos, o que também preci- 
samos de inferir são as porções que foram sendo retiradas pelos próprios agentes naturais.

Se a postura for mais eclética e se afastar, portanto, daquela visão uniformitarista, ter-se-á de olhar para eventuais diferenças existentes entre as unidades estratigráficas que, com subjectividade assumida, puderem ser identificadas e analisar o que em cada uma terá ficado registado.

Pode pensar-se que certas perspectivas de ciência, desejosas de eliminar os factores hermenêuticos, desloquem o objecto de estudo para o laboratório, a fim de verem, de facto, "o que nele existe". Mudou-se de escala, de instrumentos de análise, de metodologia. Por exemplo, o estudo das condições de formação do grão de quartzo, possível de fazer no laboratório, não é relevante para o conhecimento da hidrodinâmica

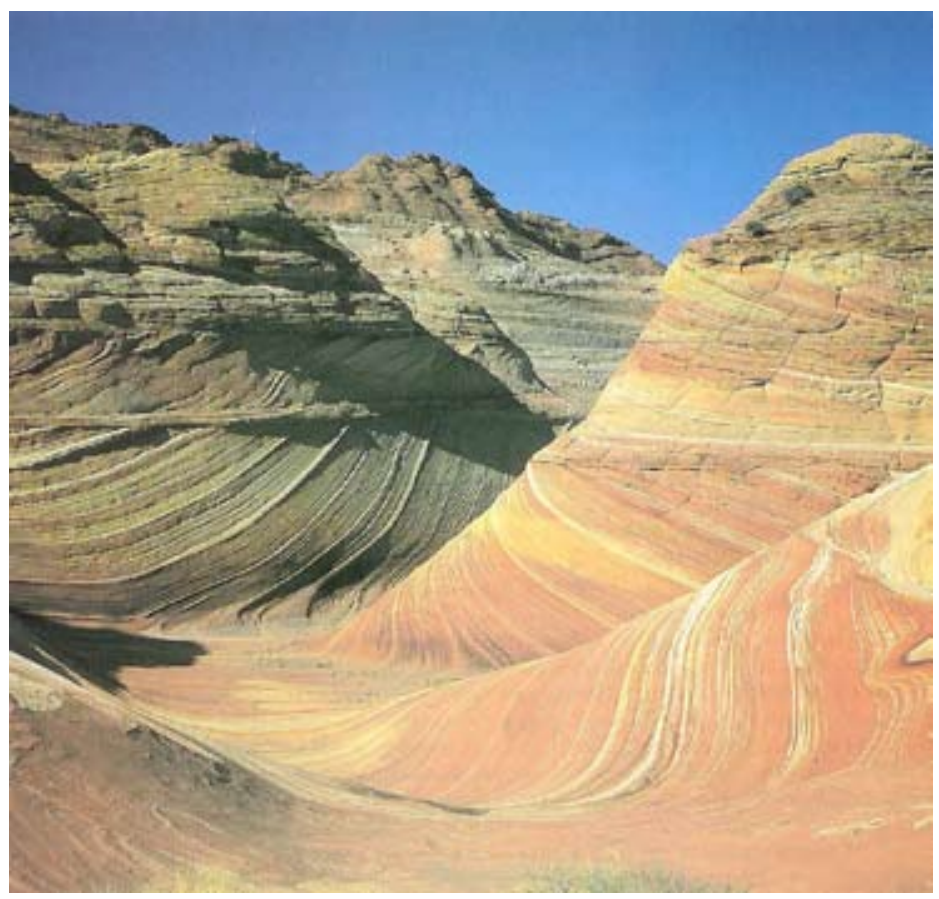

Figura 3 - Estruturas internas de sedimentação (Stanley 1993) que presidiu à génese de uma determinada bancada. Aqui, terá de se assumir a natural subjectividade inerente à própria interpretação dos resultados obtidos.

Perante um afloramento como o da figura anterior, com um elevado número de registos, o especialista é forçado a eleger, logo num primeiro momento e com alguma subjectividade inerente, aquilo que efectivamente conta como sendo estruturante. Para a compreensão das características morfológicas, os registos tectónicos podem ser cruciais; já não têm esse grau de relevância se o objecto de estudo passar a ser a natureza das estruturas sedimentares inclusas.

É assim que, em princípio, se torna difícil para qualquer experimentalista, no laboratório, mesmo com as potencialidades que hoje nos traz o computador, ultrapassar a natureza hermenêutica, que é orientadora das actividades no campo. Aliás, faria sentido, não fosse a limitação do tempo, fazer aqui uma reflexão acerca da importância que, muitas vezes, tem a própria interpretação, quando da preparação da introdução dos dados no computador que, afinal, trabalha em função dos elementos que lhe são fornecidos.

Não deve olvidar-se que o papel da hermenêutica não é desenvolver uma série de regras para efectuar uma interpretação adequada, mas tão só clarificar as condições segundo as quais a compreensão ocorre. Compreensão que, na opinião do autor, é sempre uma mistura de olhos com o pensamento, aliás, na perspectiva de Merleau-Ponty (1993).

$\mathrm{O}$ facto de os registos a necessitar de interpretação terem sido originados num tempo mais ou menos distante do nosso e num espaço geográfico e morfológico eventualmente muito diversificado do de hoje (independentemente do princípio do uniformismo) traz dificuldades reconhecidas acrescidas. O possível desaparecimento de certas informações, a seu tempo registadas, ou mesmo a eventualidade de terem sido temporalmente modificadas, contribuem para que seja mais fácil reconhecer a subjectividade da interpretação a realizar. Poderá afirmar-se que os dados estão mais difusos e susceptíveis de poderem ser interpretados de forma diferente, consoante a intencionalidade com que são estudados.

Interessante sublinhar que a dimensão hermenêutica no pensamento humano tem profundas implicações, ao nivel da compreensão da natureza do conhecimento científico e mesmo na relação entre Ciência e Sociedade. A incerteza percebe-se melhor, a complexidade assume-se de modo mais determinado, a panóplia de variáveis em jogo e a sua interaç̧ão ganham uma outra racionalidade, na procura insistente de uma visão mais holistica e global. 


\subsubsection{Carácter histórico}

Este é um aspecto muito comum no contexto das $A E S A$ especialmente quando se realiza trabalho de campo, no contexto das Ciências da Terra. O âmbito da História, em sentido lato, (integrando áreas disciplinares, como a Geologia, Antropologia etc.) é definido pela narração e pela explicação interpretativa de acontecimentos, que, com diferentes graus de intensidade, influencia a existência da Sociedade. No que efectivamente se está interessado é em conhecer aspectos específicos de uma circunstância mais geral.

Exemplificando, agora, com o caso da Ria de Aveiro (ver Fig. 4).

Ao pretendermos saber desde quando é possível atribuir-lhe identidade própria, desde quando existe com a designação que hoje tem, há a intenção de proceder a uma narrativa. O que se pretende narrar são os factores, bem como as respectivas interaç̧ões, que vêm determinando a Ria, isto é, as condições que têm operado o respectivo processo evolutivo. Procura-se igualmente saber até quando

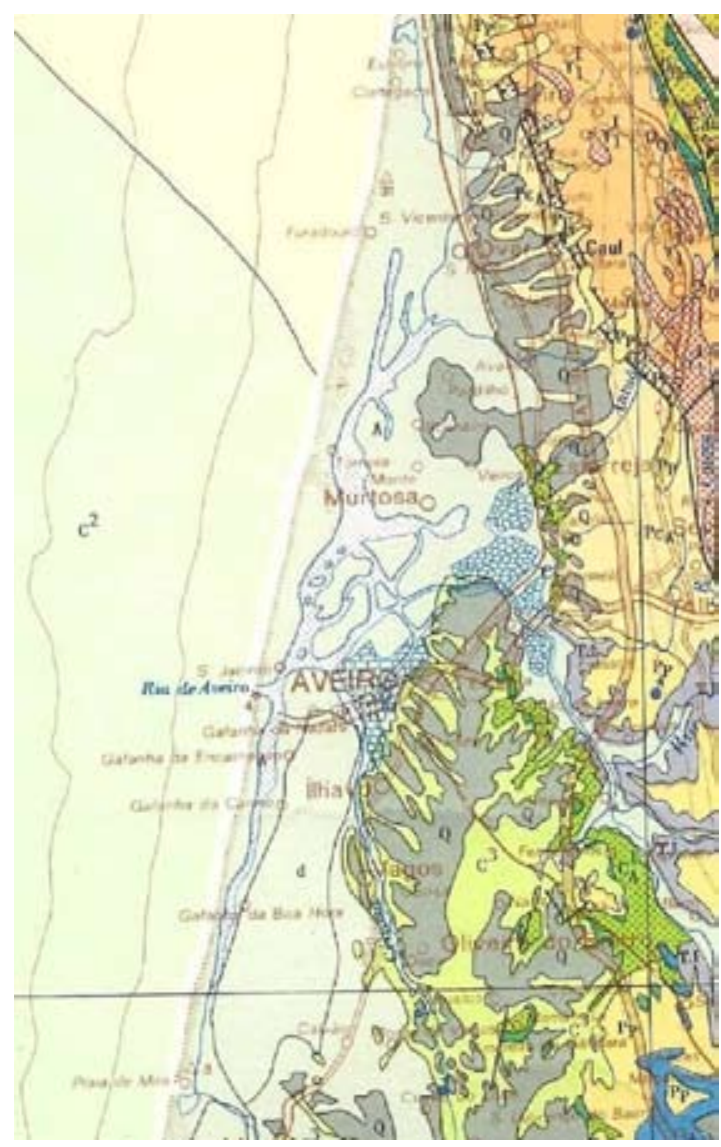

Figura 4 - Representação cartográfica da Ria de Aveiro (Carta Geológica de Portugal 1992, escala 1:500 000) é possível que a Ria evolua, sem perder a própria especificidade. A figura 4, assinalando diferentes hipotéticas fases de formação, ajuda a compreender esta problemática.

Não está aqui em causa, na perspectiva histórica, discutir a existência de uma determinada morfologia costeira, reconhecível ao longo da faixa litoral ou as dinâmicas da interface oceano-continente. É a respectiva história, neste caso a da Ria de Aveiro, que é necessário compreender. No entanto, as explicações dentro das ciências históricas envolvem instrumentos comuns a outras ciências, mas são também caracterizados por aspectos específicos, como, por exemplo, definição do objecto de estudo, dimensão a-histórica do laboratório e papel da narrativa (Frodeman 2003), as quais aqui não é possível desenvolver.

Sublinhe-se a valorização da importância que deve ser dada ao objecto de estudo situado no seu próprio enquadramento. Tal contribui para a melhor compreensão das circunstâncias em que se processa a sequência dos fenómenos naturais, convivendo com a:

- preocupação de integração da(s) parte(s) no todo que, quanto à obtenção do conhecimento, deve ser tentativa e jamais dada como completamente conseguida;

- procura de um sentido global expressa pelos mecanismos inerentes à evolução continuada, feita através de pequenos passos, ou de profundas convulsões nem sempre bem percebidas, mas quase sempre razoavelmente registadas;

- identificação de aspectos específicos determinantes, pertença de circunstâncias mais gerais.

É assim dado um contributo relevante à elaboração de perspectivas globais, mas sempre abertas à reinterpretação acerca do mundo natural.

\subsubsection{0 carácter probabilístico}

Compreender a respectiva evolução temporal faz igualmente parte das suas finalidades. Para tal, há que ir mais adiante e procurar articulações entre os elementos constituintes dos sistemas naturais, no contexto do espaço e do tempo.

Existe consenso em relação ao reconhecimento da complexidade daqueles sistemas, bem como as suas respectivas respostas às perturbações a que estão sujeitos (Mayer 2001). Sendo certo que boa parte do objecto de estudo das $A E S A$ está orientado para situações de complexidade, compreende-se que, para além do rigor metodológico usado, as 
respostas procuradas para os problemas levantados impliquem um coeficiente de probabilidade, sempre de considerar aquando do tratamento dos resultados.

A reconstituição das condições paleoecológicas de um determinado ambiente, a problemática das extinções em massa, são exemplos de proposições hipotéticas formuladas a partir de fontes registadas na natureza de forma diversa (por exemplo registo paleontológico, registo tectónico-estrutural, ...) e em situações distintas (por exemplo, boa qualidade de preservação, deficiente qualidade de preservação, sequência completa de registo, sequência incompleta do registo etc.).

Das referidas formas e situações, emerge na literatura, por exemplo, a referência às extinções em massa. O uso desta terminologia implica o pressuposto da existência de cataclismos súbitos com impacto ao nível das plantas e animais terrestres.

O célebre artigo de Alvarez e Asaro (1991) refere o sensacional crime que terá morto cerca de metade da vida na Terra, apresentando indicações do que supostamente seria o impacto do assassino asteróide gigante. A figura 5 revela um dos possíveis indícios deste desastre.

Poderá, entretanto, perguntar-se se se justifica o uso deste tipo de linguagem? Como se originou a ideia de extinção em massa? Será que as extinções, que ocorreram ao longo da história aconteceram de tal forma que tem sentido

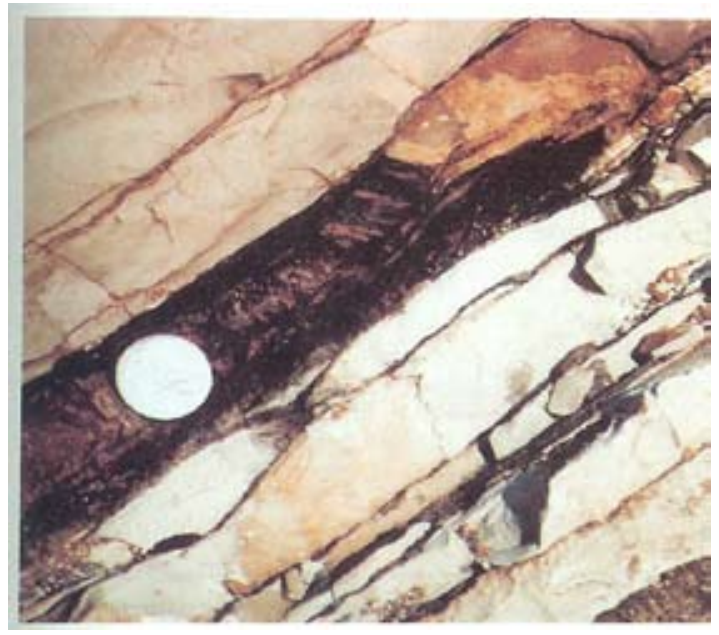

Figura 5 - Camada argilosa da passagem CretácicoCenozóico cuja concentração em irídio é cerca de 30 vezes superior às duas vizinhas. Uma percentagem elevada de calcários planctónicos está presente na camada inferior, sendo muito escassa na superior (Stanley 1993) o uso desta terminologia? Será que as extinções ocorreram de modo a merecer a designação de acontecimentos globais? Têm elas, de facto, os tais efeitos drásticos, ao nível da diversidade das espécies no globo?

De um ponto de vista histórico, a visão de Charles Lyell, de Alfred Wallace ou de Charles Darwin, não se coaduna com tal perspectiva. Contudo, recentemente, dos sete episódios do Fanerozóico, tidos como grandes extinções, dois sobressaem, o do fim do Pérmico e o do fim do Cretácico, ainda que o primeiro de proporções bem maiores do que o segundo. Apesar de tudo isso, 'terms such as 'mass extinction', 'mass killing', or 'catastrophic event' are misleading when applied to extinction episodes in the geological record" (Glen 1994, p. 234).

Tais proposições são explicadas através de modelos interpretativos, que são também emergentes da realidade, mas não são a realidade. É que poucas proposições hipotéticas correspondem a imagens de um espelho reflectindo a realidade natural.

Da reflexão que tem vindo a ser apresentada, haverá que reconhecer que as $A E S A$ tem um papel importante na elaboração do conhecimento susceptível de contribuir para responder às questões relativas à compreensão dos sistemas naturais na sua complexidade, na medida em que o objecto de estudo é, de facto, apreendido no seu próprio contexto.

No exemplo em apreciação, a metodologia de análise definida para, com a contribuição dos ambientes exteriores à sala de aula procurar responder à natureza das referidas extinções, deverá ser curricularmente bem enquadrada.

Quanto à fase da obtenção de dados, é de reconhecer que existem dois momentos em que o factor probabilidade tem de ser considerado:

- primeiro, quando, perante a panóplia de dados existentes no ambiente natural, se têm de categorizar os que são de facto relevantes, os que nada tem a ver, ou aqueles que são acessórios, relativamente à questão em causa. $\mathrm{O}$ que privilegiar, de modo a melhor compreender o tipo de extinções, os ambientes de sedimentação continental ou marinho? Tais resultados são função, por exemplo, da qualidade dos tipos de registos existentes e da interpretação efectuada acerca da respectiva interligação de diversos factores; 
- segundo, quando se procede à colheita dos próprios dados a estudar posteriormente. Por exemplo, ao recolher amostras em diferentes afloramentos, num ambiente sedimentar, com o intuito de vir a efectuar um estudo sobre permeabilidade e as suas consequências, há que considerar o grau de probabilidade daquele conjunto ser representativo daquilo que não existe a possibilidade de conhecer na totalidade.

No tocante à fase de interpretação dos dados e, portanto, ao teste das proposições hipotéticas, as quais, é bom recordar, pretendem proporcionar possibilidades de explicação relacionadas com situações naturais, o carácter probabilístico também emerge. De facto, para além das concepções e juízos de valor inerentes ao próprio sujeito - o que sempre ocorre em qualquer outra situação os ambientes exteriores à sala de aula incorporam um aspecto específico. A interpretação de uma situação ou situações pontuais não valem por si, isto é, não podem, sob pena de se tornarem irrelevantes na perspectiva da compreensão do mundo natural, deixar de ser interligadas com o contexto global em que ocorrem. Se, por exemplo, a evidência fossilífera gera dúvidas acerca das extinções em massa (Glen 1994), parece ser lícito pensar que uma extinção catastrófica está neste momento a ocorrer. Raven (1990) prevê que, no primeiro quartel do século XXI, 2 em 10 milhões de espécies animais desapareçam e cerca de 70.000 em 300.000 espécies de plantas vasculares tenham o mesmo fim.

Procurou-se aqui sublinhar que o elemento de probabilidade não é despiciendo quando se reflecte acerca da natureza do trabalho que decorre em diferentes fases.

A inclusão da dimensão probabilística na contribuição para um melhor reconhecimento, quer da natureza do conhecimento cientifico, quer dos procedimentos que a ele conduzem, é um aspecto que as AESA estão em condições de fomentar. Isto considerando que as referidas actividades contemplam a globalidade do contexto natural e, para o interpretar, têm de proceder à identificação dos factores considerados mais relevantes.

\subsubsection{0 carácter ético}

Seria bom reconhecer, com o polaco Joseph Rotablat, Prémio Nobel da Paz: "the time has come to formulate guidelines for the ethical conduct of scientists, perhaps in the form of a voluntary Hippocratic Oath" (Rotablat 1995). De facto, não faz mais sentido abordar a problemática do conhecimento científico desligada das preocupações éticas, sob pena de se correr o risco do cidadão se confrontar com uma ciência que está, à partida, fragilizada, por lhe ter sido retirado um dos seus elementos estruturantes - a dimensão humanista. Estaria, assim, a ciência em maiores dificuldades, para procurar dar resposta a uma questão essencial, que é a compreensão da relação interactiva do Homem com o ambiente. E isso deverá ser feito para o ambiente, com o ambiente e pelo ambiente, já que um dos grandes desequilíbrios planetários é o que ocorre entre o Homem e a Natureza.

A necessária modificação da postura assenta na opção individual e voluntária de cada cidadão. $\mathrm{O}$ contexto é o ambiente natural que não pode deixar de ser, também, estudado in loco, a fim de facilitar a compreensão. De acordo com outro Prémio Nobel da Química "this is the first time in human history that all human beings have been faced with learning to work and live together as one family. It is time for finally realizing that the planet on which we live is finite in space, capacity and resources" (Lee 2004).

Há ilações a retirar de tal postura. Martin (2004) vem assinalar que é relevante confrontar o aluno com propostas de trabalho efectuadas fora da sala de aula, pois isso:

- promove a sua integração com a natureza;

- potencia os seus cuidados e a sua atenção com o meio natural;

- incentiva a utilização de percursos naturais.

Se adequadamente desenhadas e integradas no currículo, as propostas de trabalho neste ambiente são um factor:

- que contribui para uma aproximação entre as Ciências e as Humanidades, assim favorecendo a articulação entre a Sociedade e a Natureza, ligando muito mais do que duas entidades, já que nem a Ciência nem a Sociedade podem ser isolacionistas (Frodeman 2003);

- que, tendo em consideração a sua interactividade, incluindo actividades hands-on e minds-on, contribuem para mais facilmente serem evidenciadas as responsabilidades de cada um com o equilíbrio do ambiente natural (Rennie 
e McClafferty 1996);

- susceptível de, pelo menos em algumas situações, serem articuladas com factores sociais e culturais (Parker \& Meldrum 1973). Atentese, por exemplo, em estudos de natureza antropológica ou etnográfica, os quais podem contribuir para que seja ganha uma atitude ética, relativamente aos costumes e às tradições de uma sociedade;

- capaz de promover o harmonioso desenvolvimento pessoal, social e educacional (Gair 1997), assim permitindo uma melhor preparação tendente a um procedimento mais compatível com uma ética global.

Pensemos num exemplo - a conservação das gravuras de Foz Côa.

A discussão e a polémica que estiveram associadas ao caso das gravuras, quando da decisão de suspender a construção da barragem, podem considerar-se exemplares, de vários pontos de vista. De facto, as notícias dos meios de comunicação, nacionais e estrangeiros, as tomadas de posição de grupos de cidadãos e das próprias escolas locais, aliadas à veemência da discussão, foram capazes de parar a construção de uma importante barragem no contexto da rede eléctrica nacional.

Não foi possível, no âmbito deste caso, deixar de considerar que ele tem várias vertentes e que não é possível pensar numa resposta única. Há, necessariamente, uma componente científica que todos reconhecem, a par de outras vertentes relevantes, de natureza social, económica e política, eventualmente menos evidentes, mas nem por isso menos importantes (Delgado Rodrigues 2003, p. 425). E até questões éticas se podem acrescentar.

Basta pensar, que logo nas tomadas de posição iniciais sobre a possível influência da albufeira sobre as gravuras, apareceram, de forma recorrente, posições que associavam a submersão à destruição das gravuras. Ausência de fundamentações plausíveis ou utilização de argumentos com inverossimilhanças eram avançados, o que eticamente é, pelo menos, discutível. Pense-se no invocar do risco de abrasão que a deposição de sedimentos acarretaria, quando é certo que se está numa albufeira!

Propostas de trabalho, no âmbito curricular fora da sala de aula que, por exemplo:

- abordem a composição mineralógica das rochas metassedimentares do Grupo do Douro - xistos, filádios e metagrauvaques - que constituem as rochas-suporte das gravuras;

- passem pela observação dos solos esqueléticos relacionados com a resistência à alteração química;

- estudem a influência da colonização biológica, especialmente de natureza liquénica;

- discutam, criticamente, argumentos usados na polémica entre as posições que defendiam as condições de exposição sub-aérea e as que apoiavam a submersão podem ser um contributo para o desenvolvimento de uma atitude de cidadania, onde a dimensão ética esteja naturalmente integrada.

Em sintese, deve sublinhar-se a dimensão ética que, permanentemente, deve ser integrada no processo de ensino em geral e das ciências em particular.

Relativamente às actividades externas à sala de aula, ficam indicadores da investigação - relação entre sociedade e natureza, responsabilização individual para com a Natureza, desenvolvimento harmonioso do cidadão na Natureza - que apontam para um espaço que privilegia uma particular articulação com a sociedade e o ambiente natural, assim contribuindo, de uma forma especifica para o desenvolvimento de uma atitude eticamente responsável.

\section{Contribuição para a consecução das finalidades da Educação em Ciência}

$\mathrm{Na}$ sequência do que foi referido na seç̧ão anterior, na qual se analisaram características das AESA pretende-se, nesta, relacionar os contributos específicos do ambiente externo à sala de aula com grandes finalidades da Educação em Ciência. A natureza dos saberes básicos para o século XXI, hoje tão necessários ao cidadão (Cachapuz et al. 2004) torna crucial o aproveitamento de sinergias entre situações de aprendizagem, que podem ocorrer em diferentes espaços, dentro e fora da sala de aula. Da literatura, verifica-se a contribuição a diversos níveis:

(i) motivação, entusiasmo e gosto, no sentido de se ganhar uma atitude de maior afectividade com o conhecimento a adquirir e com as propostas de trabalho a elaborar (Fido \& Gayford 1982; Jelinek 1998); 
(ii) colaboração, quer entre alunos, quer entre alunos e professores, de modo a promover e a estimular esta importante atitude, contribuindo assim para um bom ambiente de ensino e de aprendizagem (Hammerman 1985);

(iii) promoção da necessária cidadania de intervenção na sociedade de informação do séc. XXI com vista ao estabelecimento de perspectivas comuns de docentes e discentes acerca do trabalho de campo (Mullins 1998);

(iv) desenvolvimento de novas experiências no âmbito do ensino e da aprendizagem através, por exemplo, da possibilidade de virem a ser conceptualizadas e desenhadas estratégias diferentes e inovadoras (Informal Education and Outreach 2001);

(v) valorização da problemática referente à compreensão dos mecanismos inerentes ao mundo natural numa perspectiva holística (Mayer 2001), bem como às atitudes e aos valores que emergem da sociedade (Kahan et al. 2002);

(vi) atenção ao facto de ser bem necessário reconhecer que aqueles que trabalham no campo não o fazem in objective geographical space conceptualized by Cartesian geometry. Rather, they move through a world of implied meaning constituted by acting and perceiving body as it interacts with its environment ... the characteristics of field science provide us with an image of scientific reasoning that is much closer to the methods of everyday reasoning in our personal and political lives. Field experiences presents inescapables spatial and temporal ambiguities (Frodeman 2003, p.69-70);

(vii) valorização da observação pensada, tendente à experiênciação e interpretação de acontecimentos naturais (Praia 2003, Praia 2003, Thompson 2001);

Tendo em consideração indicadores dos estudos efectuados e, também, a experiência dos autores, apontamos cinco pontos ao nível da relação entre as $A E S A$ e a Educação em Ciência: (i)compreensão da natureza do conhecimento científico; (ii) integração de saberes e perspectiva holística; (iii) reconhecimento da incerteza e imprevisibilidade; (iv) valorização do ambiente natural; (v) trabalho cooperativo.

\subsection{Compreensão da natureza do conhecimento científico}

Tendo em consideração a oportuna síntese de Cleminson (1990) em cinco pontos, acerca do que significa hoje a ideia de Ciência, bem como da sua produção, as observações aqui feitas tê-laão em conta.

Se se considerar que, em grande parte das actividades em ambiente externo à sala de aula, o objecto de estudo no âmbito das Ciências da Terra corresponde a "situações naturais complexas" actuais ou, frequentemente, a registos correspondentes a situações que ocorreram no passado, compreender-se-á, atendendo à natureza dos dados disponíveis:

- que existe uma multiplicidade interpretativa notável e não identificável com a verdade;

- que a interrelação entre eles é forte e múltipla e não é isenta das concepções do observador;

- que, independentemente dos riscos em "ler" a evolução, que é dinâmica, a partir de registos que podem ser estáticos, o conhecimento só avançará se surgirem propostas audaciosas de trabalho, imaginativas e criativas;

- que aspectos específicos integrados numa circunstância mais geral não são fáceis de conceptualizar e serão sempre problemáticos. Compreensivelmente, e tendo em consideração que os mesmos, ou novos elementos de análise retirados do ambiente natural, podem ser reapreciados à luz de novos enquadramentos, a substituição do conhecimento previamente construído por outro posteriormente elaborado é um princípio irrecusável;

- que a relação de cumplicidade, que vem sendo assumida entre o objecto de estudo e o agente do estudo, vem espelhando o princípio de que o conhecimento não está separado do sujeito, já que é este que lhe dá forma através das interpretações, inerentes no contexto das Ciências da Terra. 
A finalizar, refira-se que mais importante do que saber se as actividades externas à sala de aula contribuem para a aquisição de informação científica, é relevante conhecer se esta experiência contribui para ajudar os participantes a pensar diferentemente acerca da ciência. Trabalhos diversos (Rennie e William 2002; Burns et al. 2003) apontam para indicadores positivos, independentemente da necessidade de reconhecerem a necessidade da continuação da investigação.

\subsection{Integração de saberes e perspectiva holística}

Se questões ligadas ao ambiente, à saúde, à segurança, à organização das cidades, não estão, de forma explícita e integrada, na agenda dos currículos de Ciências, então dificilmente a educação pode responder às suas próprias finalidades. E não bastam que estejam simplesmente, pois é necessário que sejam vistos num contexto de promoção de valores e de preocupações éticas. A sua abordagem deve privilegiar um tratamento articulado com uma intenção interdisciplinar, procurando a compreensão da Terra como um sistema marcado por permanentes e fortes interacções entre os elementos que a constituem, e das quais o contexto sócio-cultural não é despiciendo.

Nesse tipo de desenho curricular, as propostas de trabalho em ambiente externo à sala de aula, têm um papel a desempenhar, pois a sua localização facilita a aquisição de uma perspectiva integradora de saberes (Orion 2003). De facto, tendo lugar fora da sala de aula e do laboratório, as actividades de campo decorrem num espaço natural no qual, por definição, as diferentes variáveis existem individualizadas e actuam interactivamente. Aliás, e segundo a literatura, a natureza holística do ensino é um dos pontos fortes das actividades exteriores à sala de aula (Jones 2004). Tal natureza envolve preocupações hemenêuticas, éticas e históricas que nela confluem como muito bem mostra o modelo experiencial interactivo (Falk and Dierking 1992), experimentado em actividades de museologia defendendo a interacção entre três contextos: pessoal, social e físico.

As $A E S A$ promovem propostas de trabalho claramente integradoras de conceitos, e mesmo de procedimentos e de valores conduzindo à elaboração de uma perspectiva marcadamente holística (Marques 2006, Jones 2004).

\subsection{Reconhecimento da incerteza e imprevisibilidade}

Aceita-se que o conhecimento científico é construído em contexto, de forma idiossincrática, progressiva, integradora, dependendo de experiências prévias e, também, de um modo não completamente previsível. Curiosamente, o ambiente de aprendizagem que ocorre fora da sala de aula é, dentre todos os diversos ambientes em que a aprendizagem acontece, aquele que melhor reflecte a incerteza e, portanto, a imprevisibilidade acima referida.

No que especificamente se relaciona com o trabalho de campo - central no âmbito das Ciências da Terra - o controle sobre processos e a monotorização de variáveis é praticamente inexistente e, por outro lado, a interacção entre diferentes elementos, que são afinal a própria natureza, é intensa, integrando assim um leque de oportunidades de ensino e de aprendizagem, que o laboratório ou a sala de aula não podem igualar (Lock 1998). Repare-se que não faz diferença por exemplo, estudar a micropaleontologia de uma amostra de calcário jurássico em Aveiro, em Campinas, ou em Londres. Estudar o próprio Jurássico nos afloramentos portugueses do Cabo Mondego, em Portugal, ou na costa leste de Devon, na Inglaterra ou, ainda, na Bacia do Rio de Peixe no Brasil, não é necessariamente igual.

Não se pense que esta discussão tem sentido apenas em termos de espaço, pois ela pode igualmente ser estendida ao domínio do tempo. No campo, vigora a não-repetitibilidade e a contigência da successão dos acontecimentos, paralelamente com uma atitude de abertura, de relação com um fluxo de acontecimentos desprovidos de qualquer enquadramento que não seja o natural

\subsection{Valorização do ambiente natural}

De acordo com Morin (2001), os problemas particulares só poderão ser analisados e compreendidos se forem pensados no seu próprio contexto, contexto esse cada vez mais alargado à escala planetária. Tal desafio traz consigo o da complexidade, pois cada vez mais é reconhecido que as partes estão ligadas entre si.

O relevo que vem sendo dado à questão do contexto está bem articulado com o que na terminologia de Orion (2003), se refere como tipo de experiência e relevância relativamente às $A E S A$, com impacte ao nível da valorização do ambiente natural. 
O tipo de experiência a desenvolver fora da sala de aula possibilita uma mais fácil aproximação do aluno com o contexto natural e permite uma efectiva relação de proximidade entre ambos.

Pense-se, por exemplo, numa proposta de trabalho que visasse a compreensão das relações entre o biótopo e a biocenose da área de uma determinada escola. É verdade que o estudo individualizado de espécies vegetais e da litologia, bem como o cruzamento de informação oriunda de cartas topográficas, geológicas ou fitográficas dariam informações úteis. Mas sem o trabalho de campo, em sentido lato, o aluno sentirá mais dificuldades no seu processo de aprendizagem. Exactamente porque há que, como já referia Dewey, dar central importance to the role of direct experience of phenomena, and trying to present the learner with a problematic experience from which he/she could conduct genuine inquiry (Allen 2004, p. 18). Os museus de Ciência, por exemplo, são vistos como espaços que permitem elaborar significados próprios, encontrar tarefas desafiadoras, condicionar a aprendizagem, colaborar com outros e sentir efeitos positivos dos seus próprios esforços (Paris et. al. 1998)

$\mathrm{Na}$ perspectiva de Attwood (2004), as AESA permitem confrontar mais facilmente os alunos com problemas do ambiente natural, alguns criados pela actividade humana, tomar consciência deles e, até, pensar em metodologias tendentes à sua resolução.

A relevância é outra dimensão referenciada por Orion (2003). Esta deve ser entendida como estando relacionada com o facto do objecto de estudo das $A E S A$ serem parcelas do mundo natural com o qual se têm de articular. Ora, ao cidadão, esse mundo não é indiferente, na medida em que só o usufruto da natureza cabe ao homem, não se podendo, aqui, aceitar o entendimento de Descartes - um material inerte, de uma espécie de matéria-prima sujeita a impostos (Pelt e Steffan 2001, p. 172).

Reconhece-se hoje que esse mesmo mundo natural se debate, entre muitos outros, com uma série de preocupantes problemas globais - aquecimento global, desertificação e desflorestamento, sobre-exploração de recursos naturais, extinção de espécies, crescimento de bolsas de fome e de pobreza, consumo excessivo e perda da qualidade da água etc. - que não serão enfrentados de modo isolado, na medida em que são questões sistémicas.

\subsection{Trabalho cooperativo}

Da experiência dos autores, quer da que emerge das suas actividades lectivas, quer da sua própria investigação neste domínio (Marques et al. 2003), parece ser possível considerar que as actividades efectuadas em ambiente externo à sala de aula favorecem:

- o envolvimento mais efectivo dos alunos no processo de aprendizagem;

- o trabalho cooperativo entre os alunos, bem como a relação entre estes e o professor.

Recordando o que foi previamente referido quando se procurou caracterizar a natureza das $A E S A$, constata-se que à complexidade do processo de interpretação do ambiente natural deverão corresponder metodologias apropriadas que exigirão o estabelecimento de um diálogo entre alunos, sob a orientação do professor.

Também da literatura (Jones 2004), ressalta que o ambiente externo à sala de aula é assumidamente reconhecido como susceptível de oferecer experiências ricas, que permitem que, tanto alunos entre si, como alunos e professores, actuem conjuntamente em situações que potenciam uma frutuosa aprendizagem, na qual a responsabilidade pessoal não é despicienda. Tal implica que cada um dos intervenientes perceba que se podem alcançar as finalidades, se todos derem o seu contributo e trabalharem individualmente para o colectivo. Colectivo esse que passa pelo desenvolvimento de capacidades cognitivas, sociais e afectivas.

Note-se que a natureza de algumas das diversas questões, que estão em causa, quando se realizam $A E S A$, como, por exemplo: identificação de variáveis intervenientes em situações naturais, compreensão dos mecanismos inerentes ao ambiente natural, percepção da acção antrópica, promoção de atitudes e valores para com a natureza, valorização de uma atitude de cidadania, relevância da aquisição de um sentido estético implicam a necessidade de um trabalho feito em cooperação, sob pena de muitas das finalidades não serem alcançadas.

\section{Considerações finais}

Desejaríamos ter proporcionado elementos para, do ponto de vista conceptual, se reconhecerem as potencialidades que, em articulação com os diversos ambientes de aprendizagem das Ciências, 
o ambiente exterior à sala de aula possui. De facto, ele pode dar um contributo relevante para um melhor entendimento dos alunos relativamente ao modo como o conhecimento científico se desenvolve, num contexto de incerteza e imprevisibilidade, contexto esse muito próprio das Ciências da Terra. O referido ambiente também promove a aquisição de uma perspectiva integradora de saberes, os quais ajudam a uma atitude com marcado sentido ético e com responsabilização social assumida, para com o ambiente. Considerando, por um lado, a relevância que têm as Ciências da Terra no que toca à compreensão da forma como funciona o Sistema Terra, não poderá deixar de se enfatizar, por outro lado, o papel da Educação em Ciência das Ciências da Terra, em relação ao desenvolvimento, pelos alunos, de competências curriculares tendentes ao assumir de uma cidadania crítica e sustentada para com o ambiente.

A consecução destas preocupações constitui um desafio que a todos os elementos que integram os Sistemas Educativos nos vários países responsabiliza. Do ponto de vista dos autores, a necessária interacção, sistemática e inovadora, entre investigadores e professores acerca desta problemática, constitui uma pedra angular neste desafio difícil, mas possível de vencer.

\section{Referências Bibliográficas}

Adanets V. 2001. O tesouro da educação: Algumas reflexões sobre a educação de hoje e do futuro. In: Reis Monteiro A. org. 2001. Sobre o Direito à Educação. Lisboa. Centro de Investigação em Educação. Fac. Ciências Univ. Lisboa, p.53-65.

Alarcão I. org. 2001. Escola Reflexiva. Nova racionalidade. Porto Alegre. Artmed.

Allen S. 2004. Designs for Learning: Studying Science Museum Exhibits that do more than entertain. Science Education, 88(1):17-33.

Alvarez W., Asaro F. 1991. What cause the mass extinction? An Extraterrestrial Impact. Scientific American, 263:78-88.

Atwwod M. 2004. Strange Things: The Malevolent North in Canadian Literature. London: Virago.

Belitsos B. 2005. Planetary Democracy. Moving Towards a Governed World. London: Origin Press.

Bernard A.J. 1977. Quelques réflexions sur la genèse des gisemnets du type "Vallée du Mississipi". Sciences de la Terre. XXI(3):271-302.

Boavida J., Sanches M.F. 1997. Velozes sem rumo e poderosos sem causa. Revista Portuguesa de Pedagogia, XXI(1,2,3):59-87.
Braund M., Reiss M. 2004. Learning Science Outside the Classroom. London. Routledge Falmer.

Brugger W. 1983. Dicionário de Filosofia. Barcelona. Biblioteca Herder.

Burbules N., Torres C. 2004. Globalization and Education: an introduction. In Gilbert, J. ed. 2004. The Routledge Falmer Reader in Science Education. London. Routledge Falmer. p. 15-22.

Burns T.W., O'Connor D.J., Stocklmayer S.M. 2003. Science Communication: A contemporary definition. Public Understanding of Science, 12:183202.

Cachapuz A., Lopes B., Paixão M.F., Praia J. 2004. Proceedings of the International Seminar on the state of the art in Science Education Research, 15-16 October 2004. Aveiro: Univ. Aveiro.

Cachapuz A., Sá-Chaves I., Paixão F. 2004. Relatório do Estudo Saberes Básicos de Todos os Cidadãos no Século XXI. In: Estudos e Relatórios. Saberes Básicos de Todos os Cidadãos no séc. XXI. Lisboa. Conselho Nacional de Educação. p. 15-94.

Cachapuz A., Praia J., Jorge M. 2002. Ciência, Educação em Ciência e Ensino das Ciências. Lisboa. Ministério da Educação.

Cleminson A. 1990. Establishing an epistemological base for Science teaching in the light of contemporary notions of the nature of Science and how children learn science. J. Research in Science Teaching, 27(5):429-445.

Costa N. 2003. A Investigação Educacional e o seu Impacto nas Práticas Educativas: O Caso da Investigação em Didáctica das Ciências. Provas de Agregação. Aveiro: Univ. Aveiro. (Provas de Agregação).

Costa N., Graça B., Marques L. 2003. Bridging the gap between science education research and practices: a study based on academics opinions. Livro de Resumos da International Conference Teaching and Learning in Higher Education: new Trends and Innovation. Aveiro: Univ. Aveiro. 7p.

Costa N., Marques L., Kempa R. 2000. Science Teachers' Awareness of Findings from Education Research. Research in Science, Technological Education, 18(1):37-44.

Costa N., Marques L. 1999. Avaliação do Impacte da Frequência de Cursos de Mestrados no Desenvolvimento Profissional de Professores: Estudo de Um Caso. In: Livro de Resumos do III Congresso Internacional de Formação de Professores nos países de Língua e Expressão Portuguesas CIFOPLEP. Cidade da Praia, República de Cabo Verde: Instituto Superior de Educação de Cabo-Verde. p. $35-36$

Rodrigues J.D. 2003. Histórias com água e pedras. Nem sempre mole, nem sempre duras. In: Ferreira M.P. coord.. 2003. A Geologia de Engenharia e os Recursos Geológicos. Coimbra. Imprensa Univ. Coimbra. p. 419-436. (v. 2, Recursos Geológicos 
e Formação).

Delors J. 1996. Educação - um tesouro a descobrir. Porto: Ed. Asa.

Falk J. H., Dierking 1992. The museum experience. Washington, DC: Whalesback Books.

Fensham P.J. 2004. Defining an Identity: The Evolution of Science Education as a Field of Research. Dordrecht: Kluwer Acad. Publ.

Fido H.A., Gayford C.G. 1982. Field work and the biology teacher: A survey in secondary schools in England and Wales. Journal of Biological Education, 16(1): 27-34.

Foucault M. 1996. As palavras e as coisas. Lisboa. Edições 70.

Fraser B.J., Tobin K.G. 1998. International Handbook of Science Education. London. Kluwer Acad. Publ.

Frodeman R. 2003. Geo-Logic. Breaking Ground Between Philosophy And The Eareth Sciences. New York State University of New York Press.

Frodeman R. 1995. Geological reasoning: Geology as an interpretive and historical science. Geol. Soc. Am. Bull., 107(8):960-968.

Gair N. P. 1997. Outdoor Education. Theory and Practice. London and Wellington: Cassel.

Glen W. 1994. Mass-Extinction: How science works in a crisis. Stanford. Stanford Univ. Press.

Glossary of Literacy Terms. 1999. Lingua Links Library. Version 4.0. SILL International. URL: http:www. ethnoloque.com/LL docs/contents.asp. (Publ. em CD-ROM).

Hammerman D. 1985. Teaching in the Outdoors. Third Edition. Interstate Printers, Publishers, Inc. Danville, IL. ERIC Document Reproduction Service Number ED282718.

Hodson D. 2004. Time for Action: Science Education for an alternative future. In Gilbert, J. ed.. The Routledge Falmer Reader in Science Education. London. Routledge Falmer.

Jelinek D.J. 1998. Student perceptions of the nature of science and attitudes towards science education in an experiential science program. Paper presented at the Annual Meeting of the National Association for

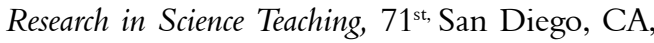
April. ERIC Document Reproduction Service Number ED418875.

Jenkins E.W. 2000. Research in Science Education: Time for a Health Check? Studies in Science Education, 35:1-26.

Jones M. 2004. Disconnections between outdoor programs and education principles. Comunicação Apresentada na International Outdoor Education Research Conference. La Trobe University Bendigo. Victoria, Auatralia. Disponível em http:www. latrobe.edu.au/oentC_D_conference_2004/ Conference\%20CD/papers. $\bar{h}$ tml

Kahan Jr. P.H., Kellert S.R. eds. 2002. Children and Nature; Psychological, Sociocultural, and Environmental
Investigations. Cambridge: MIT Press.

Knorr-Cetina Karin. 1999. A Comunicação na Ciência. In: F. Gil Org.. A Ciência tal qual se faz. Lisboa, Ed. Sá da Costa, p. 375-393.

Lee Y. 2004. Science, Information and Ethics. TWAS Newsletter, 16(2):13-15.

Lock R. 1998. Fieldwork in the life sciences. International Journal of Science Education, 20(6):633642.

Lopes J.B.P., Praia J., Guerra C., Cachapuz A.F. 2005. Epistemologia da didáctica das ciências: um estudo sobre o estado da arte da investigação. Enseñanza de las Ciências, 2005 (Número Extra, VII Congreso).

Loureiro M. J., Santos M. C., Marques L., Neto A., Costa N., Praia J., Vasconcelos C. e Oliveira T. 2005. In: D. Koliopoulos, A. Vavouraki. Research in School Practice in Science Education: Teachers' perceptions about the difficulties of the dialogue. In: Science Education at Cross Roads: meeting the Challenges of the 21th Century. Athens. Association For Science Education EDIFE. p. 241-254.

Marques L. 2006. Educação em Ciência: Potencialidades dos Ambientes Exteriores à Sala de Aula. Provas de Agregação. Aveiro: Univ. Aveiro.

Marques L., Praia J., Carrascosa J., Edwards M., GilPerez D., Vilches A., Thompson D. (1998). The Current Planetary Crisis: a Missing Dimension in Science Education. In: Science Education, Experimental Science Activities and Environmental Sustainability. ED. Peter Lang GmbH. Série "Umweltbildung, Umweltkommunikation und Nachhaltigkeit - Environmental Education, Communication and Sustainability". Hamburg, Alemanha.

Marques L., Praia J. 2007. Educação em Ciências: actividades exteriores à sala de aula. In: Simpósio de Pesquisa em Ensino e História de Ciências da Terra, 1, e Simpósio Nacional sobre Ensino de Geologia no Brasil, 3, Campinas, 4-8.09.2007. Palestra... Campinas, DGAE/IG/Unicamp. (comun. inédita).

Marques L., Costa N., Pombo L. 2005. A Formação Pós-Graduada de Professores de Ciências: Concepção, Implementação e Avaliação de uma Proposta de Intervenção. In: Encontro Nacional de Educação em Ciências, 11, Encontro de Educação para Nova Cultura da Água, 1, Porto, 2005. Actas... Porto, Escola Superior de Educação. 5 pp. (CD-ROM).

Martin P. 2004. Outdoor Education for Human/Nature Relationships. In: International Outdoor Education Research Conference. Bendigo, Victoria, Australia, La Trobe Univ. 15p. URL: http:www. latrobe.edu.au/oentC_D_conference_2004/ Conference\%20CD/papers.html. Acesso em 
30.10.2006.

Mayer V. 2001. Global Science Literacy in the Secondary School Curriculum. In: Marques L., Praia J. orgs. Geociências nos Currículos dos Ensinos Básico e Secundário. Aveiro: Univ. Aveiro. p. 333355.

Merleau-Ponty M. 1962. The Phenomonology of Perception. London. Routledge, Kegan Paul.

Orion N. 2002. The outdoor as a central learning environment in the Global Science Literacy framework: from theory to practice. In: V. Mayer. ed. 2002. Implementing Global Science Literacy. The Ohio State Uiniversity. p. 53-66.

Pabos J.L. 2004. Complejidad y Dualidad en el Sistema Terra. Enseñanza de las Ciencias de la Tierra, 12(3):243-247.

Paris S.G., Yambor K.M., Packard B. 1998. Handson biology: a museum-school-university partnership for enhancing students' interests and learning in science. The Elementary School Journal, 98(3):267- 289.

Pelt J.M.E., Steffanm F. 2001. La Terre en Héritage. Paris, Lisboa: Librairie Arth.

Praia J. 2003a. Epistemologia da Ciência. Um contributo para uma fundamentação em Educação em Ciência. Relatório da Disciplina de Epistemologia da Ciência. Aveiro: Univ. Aveiro. Provas de Agregação.

Praia J. 2003b. Relatório da Disciplina de Epistemologia da Ciência. Um contributo para uma Fundamentação em Educação em Ciência. Aveiro: Univ. Aveiro. (Provas de Agregação).

Rennie L.J., McClafferty T.P. 1996. Science centres and science learning. Studies in Science Education, 21:160-82.

Rennie L.J., William, G.F. 2002. Sciences Centres and Scienctific Literacy: promoting relationship with science. Science Education, 86:706-726.

Stanley S.M. 1973. Exploring Earth and Life Through Time. New York: W. H. Freeman Co.

Thompson D. 2001. Towards an earth-environmental science education for all aged 4-16. In: Marques L., Praia J. orgs. Geosciences in the Secondary School Curriculum. Aveiro: Univ. Aveiro. p. 300-331.

White R.T. 2001. The revolution in research in science education. In: V. Richardson. ed. 2001. Handbook of research on teaching. 4 ed. Washington DC: American Educational Research Association. 